\title{
Isobaric Thermal Expansion and Isothermal Compression of Powdered NiFe Based Alloys Studied by In-Situ EDXRD
}

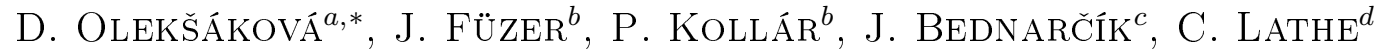

${ }^{a}$ Dpt. of Appl. Mathematics and Informatics, Fac. of Mechanical Eng., TUKE, Letná 9, 04200 Košice, Slovakia

${ }^{b}$ Institute of Physics, Faculty of Sciences, P. J. Šafárik University, Park Angelinum 9, 04154 Košice, Slovakia ${ }^{c}$ HASYLAB am Deutschen Elektronen Synchrotron, DESY, Notkestrasse 85, D-22607 Hamburg, Germany

${ }^{d}$ Geo Forschungs Zentrum Potsdam at DESY/Hasylab, Notkestrasse 85, D-22607 Hamburg, Germany

The aim of the present work was to study the isothermal compression and isobaric thermal expansion behaviour of ball-milled NiFe (81 wt.\% of Ni) and NiFeMo (79 wt.\% of Ni, 16 wt.\% of Fe) alloy and follow its phase evolution when exposed to high pressure and temperature. In-situ pressure-temperature energy dispersive X-ray (EDXRD) diffraction experiments were performed at the MAX80 instrument (beamline F2.1). The compressibility of NiFe alloy at $400{ }^{\circ} \mathrm{C}$ was evaluated for pressure values of up to $3.5 \mathrm{GPa}$. The EDXRD spectra revealed the presence of cubic $\mathrm{FeNi}_{3}$ phase as determined from the shift of (111), (200) and (220) reflection lines in corresponding EDXRD spectra.

DOI: 10.12693 /APhysPolA.126.128

PACS: 75.50.Bb, 61.05.cp

\section{Introduction}

In the recent years, nickel-iron alloys have generated a lot of the interest in the both fundamental and applied science. Their remarkable magnetic properties have made them the subject of study over the last about half of a century. The highest permeability and near to zero magnetostriction characterize the alloys with the nominal composition $\mathrm{Ni}_{81} \mathrm{Fe}_{19}$, called permalloy. Supermalloy $\mathrm{Ni}_{79} \mathrm{Fe}_{16} \mathrm{Mo}_{5}$ has an improved loss characteristic over permalloy materials, which target at a higher operating frequency [1].

After heat treatment permalloy has the initial permeability much larger than the one of the pure iron and is produced usually in the form of thin sheets. Therefore it is logical to attempt to prepare such material in more "bulk" form, for example in the form of a cylinder or a ring, which would be more convenient for some industrial applications. One of the methods, suitable for this preparation is for example the mechanical milling or mechanical alloying.

Mechanical milling is a useful powder processing technique that can produce a variety of equilibrium and nonequilibrium alloy phases $[2,3]$. Some researches concerning $\mathrm{Ni}-\mathrm{Fe}, \mathrm{Ni}-\mathrm{Fe}-\mathrm{Mo}$ powders system produced by mechanical milling were reported in [4-6].

\section{Experimental}

We have prepared two types of powder samples [4]. The sample NiFe was prepared by mechanical milling of microcrystalline ribbon $\mathrm{NiFe}(81 \mathrm{wt} . \%$ of $\mathrm{Ni}$ ) obtained by melt-spinning, which is suitable for milling. The sample NiFeMo was prepared by the milling of the swarfs of NiFeMo (79 wt.\% of $\mathrm{Ni}, 16$ wt.\% of $\mathrm{Fe}$ ), which were

*corresponding author; e-mail: denisa.oleksakova@tuke.sk prepared from an ingot by turning. We used swarfs, because it was not possible to prepare ribbons with this chemical composition. The milling of both samples was performed in a protective argon atmosphere in a highenergy planetary ball mill (RETSCH PM4000) with ballto-powder-ratio of $6: 1$ and with a speed of $180 \mathrm{rpm}$ $[4,5]$. The $\mathrm{Ni}_{79} \mathrm{Fe}_{16} \mathrm{Mo}_{5}$ sample was milled in a vial cooled in liquid nitrogen. The temperature stability of the high-energy ball-milled $\mathrm{Ni}_{81} \mathrm{Fe}_{19}$ and $\mathrm{Ni}_{79} \mathrm{Fe}_{16} \mathrm{Mo}_{5}$ specimens was investigated by in situ angular-dispersive X-ray diffraction using high-resolution diffractometer at the B2 beamline in HASYLAB/DESY. Heating experiments were performed in situ, using an image plate detector and a STOE furnace. In-situ pressure-temperature energy dispersive X-ray diffraction experiments were performed at the MAX80 instrument (beamline F2.1). The compressibility of $\mathrm{Ni}_{81} \mathrm{Fe}_{19}$ alloy at $400{ }^{\circ} \mathrm{C}$ was evaluated for pressure values of up to $3.5 \mathrm{GPa}$. The thermal expansion of $\mathrm{Ni}_{79} \mathrm{Fe}_{16} \mathrm{Mo}_{5}$ alloy under pressure of $3.9 \mathrm{GPa}$ was evaluated within temperature range $30-800{ }^{\circ} \mathrm{C}$.

\section{Results}

The aim of this work was to study the isothermal compression and isobaric thermal expansion of ball-milled $\mathrm{Ni}_{81} \mathrm{Fe}_{19}$ and $\mathrm{Ni}_{79} \mathrm{Fe}_{16} \mathrm{Mo}_{5}$ alloys and follow their phase evolution when exposed to high pressure and temperature.

The diffraction patterns collected upon heating of the powder, prepared by the milling of the ribbon $\mathrm{Ni}_{81} \mathrm{Fe}_{19}$ for 15 hours at constant heating rate, are shown in Fig. 1. These investigations confirmed that $\mathrm{Fe}-\mathrm{Ni}_{3}$ phase as well as fcc Fe-Ni solid solution occur in powdered NiFe samples and this single-phase system is precondition for the creation of $\mathrm{Ni}-\mathrm{Fe}$ based soft magnetic materials. These results correspond with previous DSC results (Netzsch DSC 404) [4] and with results of X-ray diffraction, obtained with Fe-filtered $\mathrm{Co}-\mathrm{K}_{\alpha}$ radiation (Philips $\mathrm{PW}$ 1050) with diffracted-beam graphite monochromator [6]. 


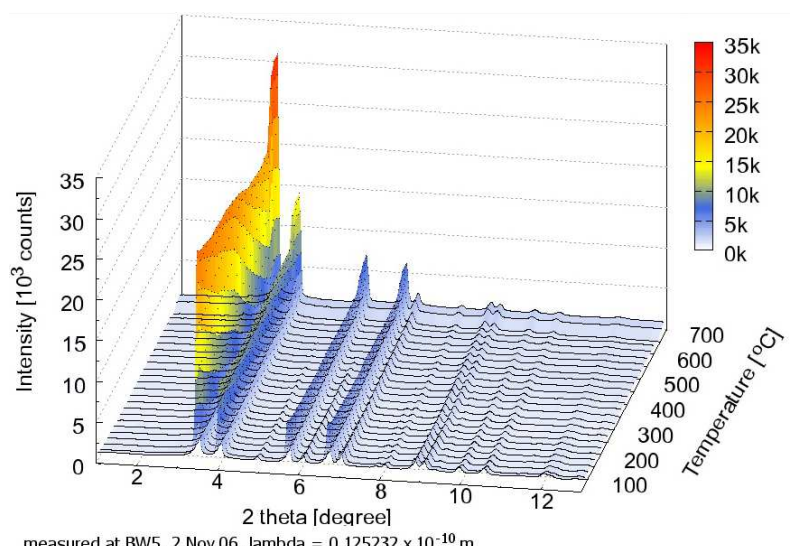

Fig. 1. XRD patterns of the in-situ annealing of sample NiFe, milled for 15 hours at BW5.

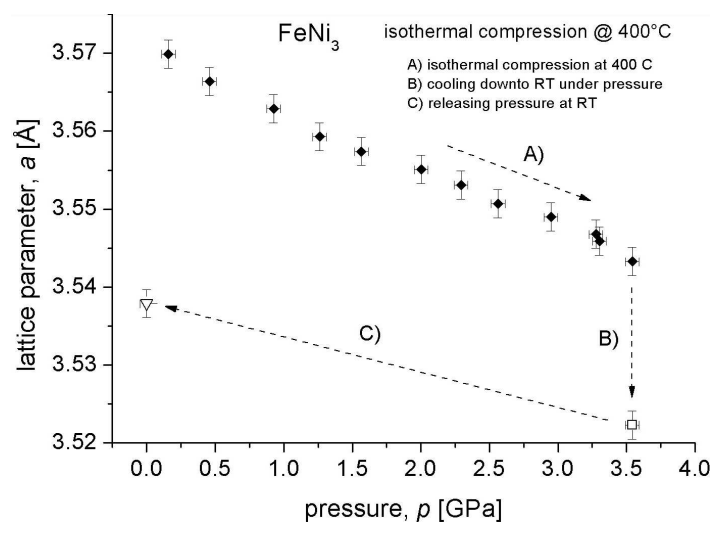

Fig. 2. The evolution of the lattice parameter of cubic $\mathrm{FeNi}_{3}$ phase of the sample $\mathrm{Ni}_{81} \mathrm{Fe}_{19}$ during $\mathrm{A}$ ) isothermal compression at $400{ }^{\circ} \mathrm{C}$, B) cooling down to room temperature under pressure of $3.5 \mathrm{GPa}$ and $\mathrm{C}$ ) after releasing pressure at room temperature.

The compressibility of $\mathrm{Ni}_{81} \mathrm{Fe}_{19}$ alloy at $400{ }^{\circ} \mathrm{C}$ was evaluated for pressure values of up to $3.5 \mathrm{GPa}$. The EDXRD spectra revealed the presence of cubic $\mathrm{FeNi}_{3}$ phase. Figure 2 illustrates the experimental compression behaviour of major constituent phase $\mathrm{FeNi}_{3}$, as determined from the shift of (111), (200) and (220) reflection lines in corresponding EDXRD spectra [7]. The thermal expansion of $\mathrm{Ni}_{79} \mathrm{Fe}_{16} \mathrm{Mo}_{5}$ alloy under pressure of $3.9 \mathrm{GPa}$ was evaluated within temperature range 30 $800^{\circ} \mathrm{C}$. The EDXRD spectra revealed the presence of cubic $\mathrm{FeNi}_{3}$ phase. Figure 3 shows the temperature dependence of the lattice parameter $a$ of major constituent phase $\mathrm{FeNi}_{3}$ as determined from the shift of (111), (200) and (220) reflection lines in corresponding EDXRD spectra. After reaching $500^{\circ} \mathrm{C}$, the thermal expansion of $\mathrm{cu}-$ bic lattice deviates from linear behaviour and tends to increase at a higher rate [7].

\section{Conclusions}

We found out that the decrease of lattice parameter of cubic $\mathrm{FeNi}_{3}$ after isothermal compression of ball-milled

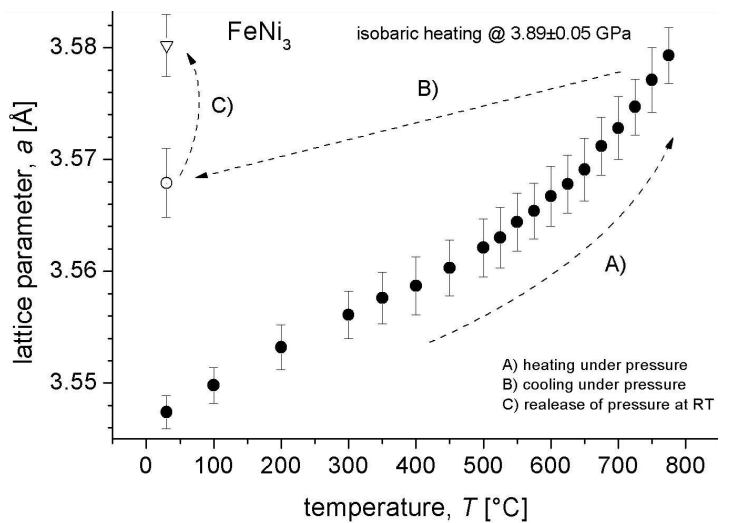

Fig. 3. The evolution of the lattice parameter of cubic $\mathrm{FeNi}_{3}$ phase of the sample $\mathrm{Ni}_{79} \mathrm{Fe}_{16} \mathrm{Mo}_{5}$ during A) isobaric heating at $3.9 \mathrm{GPa}, \mathrm{B}$ ) cooling down to room temperature under pressure of $3.9 \mathrm{GPa}$ and $\mathrm{C}$ ) after releasing pressure at room temperature.

$\mathrm{Ni}_{81} \mathrm{Fe}_{19}$, and subsequent release of compression and temperature, is about $0.03 \AA$. The increase of lattice parameter of cubic $\mathrm{FeNi}_{3}$ after isobaric thermal expansion of ball-milled $\mathrm{Ni}_{79} \mathrm{Fe}_{16} \mathrm{Mo}_{5}$ alloy is also about $0.03 \AA$. High compression and heating, which simulate the conditions at milling of NiFe alloys, influence negligibly the crystal structure. We assume that compaction of a milled NiFebased powder results in material with a similar structure as the one of the origin alloy.

\section{Acknowledgments}

This work was supported by the Slovak Research and Development Agency through project APVV-022210 MAGCOMP, by the projects, nanoCEXmat I, ITMS 26220120019 and nanoCEXmat II, ITMS: 26220120035 , supported by the Operational Program "Research and Development" financed through European Regional Development Fund and by the Scientific Grant Agency of the Ministry of Education of Slovak Republic and the Slovak Academy of Sciences, projects Nos. VEGA 1/0861/12 and No. 1/0862/12.

\section{References}

[1] R.C. O'Handley, Modern Magnetic Materials, Wiley, New York, 2000.

[2] R. Besmel, M. Ghaffari, H. Shokrollahi, B. Chitsazan, L. Karimi, J. Magn. Magn. Mater. 323, 2727 (2011).

[3] B.V. Neamtu, O. Isnard, I. Chicinas, V. Pop, J. Alloys Compd. 509, 3632 (2011).

[4] D. Olekšáková, P. Kollár, J. Füzer, M. Kusý, S. Roth, K. Polanski, J. Magn. Magn. Mater. 316, e838 (2007).

[5] D. Olekšáková, J. Füzer, P. Kollár, T. Švec, J. Kováč, J. Briančin, K. Polański, Czechoslovak Journal of Physics 54, D93 (2004).

[6] D. Olekšáková, S. Roth, P. Kollár, J. Füzer, J. Magn. Magn. Mater. 304, e730 (2006).

[7] D. Balzar, H. Ledbetter, Journal of Appl. Cryst. 26, 97 (1993). 